open@ACcess

Authors' contribution:

A) conception and design of the study

B) acquisition of data

C) analysis and interpretation of data

D) manuscript preparation

E) obtaining funding

Received: 17.10 .2020

Accepted: 24.08 .2021

\section{Physical Activity Using Social Media During the COVID-19 Pandemic: The Perceptions of Sports Science Students}

\author{
Samuel López-Carril 1,2 A-D (D, Paloma Escamilla-Fajardo*1A-C (D, \\ Mario Alguacil-Jiménez ${ }^{1 \mathrm{C}-\mathrm{E}}$ (D) \\ ${ }^{1}$ Department of Physical Education and Sport, Universitat de València, Spain \\ ${ }^{2}$ Department of Physical Activity and Sports Science, Universidad de Castilla-La \\ Mancha, Toledo, Spain
}

*Correspondence: Paloma Escamilla-Fajardo; Department of Physical Education and Sport, Universitat de València; 3 Gascó Oliag; 46020, Valencia, Spain; email: paloma. escamilla@uv.es

\begin{abstract}
During the period of the COVID-19 lockdown, sports organizations and companies had to look for new ways to connect with their customers by offering physical activity (PA) alternatives to do at home. This study explores the perceptions of 175 undergraduate sports science students regarding their social media (SM) and PA patterns during the first Spanish COVID-19 lockdown period (March to May 2020). From their homes, the students completed an ad hoc online questionnaire. The data was analyzed using SPSS 23.0 software to perform descriptive and inferential analysis (t-test). The results show that the participants used SM during the COVID-19 lockdown to visualize or practice PA, perceiving SM platforms as channels through which to motivate themselves to perform PA, promote it or learn about new training disciplines. Significant gender differences were found with respect to the practice of PA using SM, with females showing higher scores than males. YouTube and Instagram were the most used SM platforms for viewing or practicing PA. In terms of practical implications, this study reinforces the role of SM in sports management for creating opportunities to connect with customers and offer innovative PA proposals in the challenging period brought on by COVID-19.
\end{abstract}

Key words: Social media, COVID-19, lockdown, physical activity, sport

\title{
Introduction
}

In its weekly epidemiological update (25 April 2021), the World Health Organization (WHO) reported more than 146 million cases and over 3 million deaths globally from COVID-19 illness (WHO, 2020a). Due to the COVID-19 outbreak, most countries have been forced to adopt protective policies such as physical distancing and social isolation to combat the coronavirus SARS-CoV-2. Among the restrictions that have brought about a remarkable change in many people's daily lives are the cancellation of high participation events and sports leagues, travel restrictions (Stanton et al., 2020), the suspension of social gatherings, and the closure of schools and universities (Parnell et al., 2020). Whether in one form or another, COVID-19 has had a direct socio-economic impact on the primary, secondary, and tertiary sectors (Nicola et al., 2020), creating a "new normality" that is directly reshaping the way people interact and a wide range of spheres of life (Dwivedi et al., 2020). Instances of this include changes to work, education, access to information, and consumption of sports goods and services, among other areas. 
The field of sport has been no exception. The widespread need to minimize the possibilities of COVID-19 transmission has had an enormous impact on sports and exercise (Yeo, 2020). The consequences of the long-term impact of the virus on sport are still beginning to emerge. We still do not know what sport, in its different expressions (e.g., professional, amateur, and recreational), will be like after the pandemic, although it is likely that the virus will become a regular feature of life in the years to come (Evans et al., 2020). Nevertheless, as a result of the imposition of political physical distance and social isolation measures affecting the entire population, sports clubs and organizations have already paused face-to-face activity, and sports centers and facilities have been closed (Hayes, 2020). Lockdowns have forced competitions and other types of organized sports activities to be cancelled or postponed. These restrictions negatively affect daily sports practice (Hammami et al., 2020), which has implications for health and well-being. Thus, some European countries allowed outdoor exercise during their lockdowns (e.g., Germany and the UK), while other countries, such as Sweden, avoided coercive strict lockdowns precisely because of the health consequences of preventing people from exercising (Wackerhage et al., 2020). These policies towards physical activity (PA) and sport are in line with the opinions of experts who advocated for staying physically active to prevent future health problems (Constandt et al., 2020).

Considering the situation described above, the sports sector has been pushed to explore or strengthen other pathways for citizens to engage in PA. Among them, proposals for PA on social media (SM) have stood out. While the academic literature previously highlighted the important role SM plays in the sports industry (Abeza et al., 2015; Filo et al., 2015), it has been during the COVID-19 lockdown periods that its use in the sporting context has become particularly relevant (e.g., Hayes, 2020). The requirement for citizens to be confined within their homes has led to increased online consumption by the population as well as a large growth in the use of SM (Nabity-Grover et al., 2020). This fact has allowed platforms such as Instagram, Facebook, YouTube, and TikTok to become venues where society has been able to view multiple proposals for visualizing or performing PA at home and users have had the opportunity to connect (Hayes, 2020; Su et al., 2020). Trainers, fitness centers, and other types of sports entities have adapted their proposals during confinement to provide alternative services to their customers and attempt to attract new customers (Mutz et al., 2021; Stanford \& Salles, 2021).

Given the impact of home-based PA enhanced through SM on the sports industry (Hayes, 2020), this article focuses on the perspectives that a group of Spanish sports science university students have had on this new phenomenon during the lockdown period. As students of sports science, this population group in particular has a predisposition towards PA. This study considers their perceptions of the use of SM to promote PA. The assumption here is that they will be future deliverers of PA proposals to ensure proper physical and mental health. It is therefore important to better understand their perceptions of the potential of SM for channeling PA proposals, as SM platforms will be important tools in their professional future. Therefore, the study has potential implications in the field of health policy development using SM, for the introduction of SM in university courses, and for sports industry professionals who can exploit SM to develop new products and services for PA delivery adapted to the pandemic context.

\section{Lockdown, home-based PA, and SM}

According to Ratten (2020), "the sport industry is one of the most affected by the restrictions put in place because of the virus" (p. 1). In the quarantine context, with the population unable to go outside for physical practice, there is a higher risk of sedentary behavior that adversely affects health. As a result, the WHO (2020b) made a range of recommendations for avoiding physical inactivity such as "learn simple daily physical exercises to perform at home, in quarantine or isolation so you can maintain mobility and reduce boredom" (p. 5).

PA at home has received specific attention from several studies that have pointed out its positive impact on the health of practitioners and its ability to assist with recovery or help with overcoming diverse injuries or illnesses (e.g., Coughlin et al., 2019; Flynn et al., 2019; Pekmezi et al., 2017). Considering that there is no possibility of going outside in the lockdown context, home-based PA can be valuable for maintaining an active population and preventing tendencies towards sedentary behavior by promoting the health of the population (Shariat et al., 2020). Therefore, it is recommended that people stay active by doing PA at home (Hammami et al., 2020).

Various types of PA can be done at home. Nevertheless, there is sometimes a lack of motivation to practice PA. This may happen because people are used to doing PA in a social context with other people, and many have never done PA at home before. In this sense, SM, "a group of Internet-based applications that build on the ideological and technological foundations of Web 2.0, and that allow the creation and exchange of User Generated Content" (Kaplan \& Haenlein, 2010, p. 61), has boosted the development of PA at home by encouraging populations to practice PA (Hayes, 2020). The reason for this is that during this period of lockdown, the populations of several countries, including Spain, were not allowed to leave their homes to engage in PA. For example, SM promoted online PA 
challenges and allowed PA trainers and influencers to support and inspire practitioners, making at-home PA more social in nature (Stanford \& Salles, 2021; Su et al., 2020). Therefore, SM allowed a greater practice of PA in the periods of restrictions, helping prevent an increase in sedentary lifestyles caused by the lockdown situation (Mutz et al., 2021; Wackerhage, 2020). The success of SM in promoting PA at home benefited from the general growth of SM use by the population during the lockdown. Indeed, due to the restrictions arising from COVID-19, the frequency of SM use has increased considerably (Nabity-Grover et al., 2020). According to We Are Social (2020), SM usage increased from the pre-lockdown period by $58 \%$ in the population aged $16-24,50 \%$ in the $25-34$ age group, $42 \%$ in the $35-44$ age group, $34 \%$ in the $45-54$ age group, and 32\% in the 55-64 age group. Considering this data and the situation of social restrictions, it is understandable that the ways in which organizations or individuals connect with their clients or followers has changed (Ratten, 2020).

SM is used through technological devices such as smartphones and other wearable digital devices that can offer significant productivity opportunities and benefits (Gao \& Lee, 2019). These technological devices are elements that inseparably accompany the majority of the population. Therefore, it is also essential to consider these devices that make SM accessible as avenues for accessing the population to encourage them to engage in PA (Barkley et al., 2020). During the periods of confinement caused by the pandemic, professionals offering PA products and services needed new channels to reach their customers. Within this context, "social media and in particular online communities are a way that businesses are connecting with their customers" (Ratten, 2020, p. 5). Nevertheless, the opportunities offered by SM to the sports industry should be taken with caution as excessive smartphone use can have negative health consequences (Elhai et al., 2020). For instance, SM can encourage addictions, sedentary lifestyles, and sleeping and self-esteem disorders and can even facilitate the consumption and propagation of fake news, among other things, as several studies have warned (e.g., Baccarella et al., 2018; Bailin et al., 2014). Therefore, considering these risks, it is important to develop policies and initiatives that educate and guide citizens to use mobile devices and SM responsibly and take advantage of the potential of these tools to catalyze PA proposals that lead to healthier lifestyles.

The relationship between COVID-19 and healthy PA behaviors is something that has quickly caught the attention of researchers who have addressed this issue in recent literature (e.g., Constandt et al., 2020; Goethals et al., 2020; Schnitzer et al., 2020). Despite these valuable studies, specific research exploring young people's perceptions of the possibilities offered by SM for practicing PA under the COVID-19 lockdown scenario have not yet been carried out. In pursuing this, the perceptions of university students studying sports science were considered a suitable sample. This population group comprises regular consumers of PA who will soon enter the sports industry as PA prescribers. Given this gap in the literature, the main objectives of this work are threefold: first, to identify which SM platforms were the most used by sports science students to visualize PA during the COVID-19 lockdown; second, to identify which SM platforms were the most used by sports science students to perform PA during the COVID-19 lockdown; and third, to explore the sports science students' perceptions about the relationship between SM and the practice of PA during the COVID-19 lockdown.

\section{Methodology}

\section{Context and participants}

This study involved undergraduate students $(n=175)$ from the second and third year of the Bachelor's Degree in PA and Sports Science at the University of Valencia in Spain. Data collection was undertaken by convenience sampling. Since the participants were students at the same university, we had the possibility of connecting with them online during the teaching period of the first Spanish lockdown (from March to May 2020). A total of 76.6\% $(n=134)$ of the students were male, and $23.43 \%(n=41)$ were female. The mean age of the participants was 21.72 years $(\mathrm{SD}=3.44)$, with an age range of 20 to 50 years old. All students participated voluntarily and gave their signed consent so that the data obtained could be used for academic purposes with their anonymity guaranteed. The study was carried out in accordance with the Declaration of Helsinki (World Medical Association, 2013).

\section{Instrument, procedure, and data analysis}

Given the lack of literature on PA using SM during the COVID-19 pandemic, we used LimeSurvey to create a new ad hoc online scale of eight questions assessing the perspectives of the sample regarding the three objectives of our study. The scale is called "Lockdown PA Practice through SM" (LPAPSM). The scale items were developed by the authors to measure diverse perceptions about the relationship between SM and the practice of PA during the COVID-19 lockdown (e.g., "SM facilitates the promotion of PA during lockdown," "SM is more important in 
promoting PA and sports during lockdown than before," "After the lockdown, I will continue to use SM to follow training proposals."). The LPAPSM scale was filled in using five Likert-type scale response anchors, with 1 being "strongly disagree" and 5 being "strongly agree." Besides the LPAPSM scale, sociodemographic items such as gender, age, and pre-COVID-19 and COVID-19 lockdown SM usage patterns were included.

To analyze the psychometric properties of the LPAPSM scale, an exploratory factorial analysis (EFA) was carried out using the software FACTOR, following the recommendations established by Lloret-Segura et al. (2014). The factorial analysis was carried out by means of the maximum likelihood extraction method with quartimin rotation. To determine the number of factors that yield the set of items, a parallel analysis was carried out (Timmerman \& Lorenzo-Seva, 2011). To determine the fit of the proposed model, the values of the root mean square of residuals (RMSR) and the gamma index of the goodness-of-fit (GFI) were used, as suggested by Tanaka and Huba (1989). In addition, to ensure the sample fit, it was verified that the value of Kaiser-Meyer-Olkin (KMO) was greater than $.50(\mathrm{KMO}=.78)$, which indicates the degree to which each element is predictable by the others and, therefore, ensures the relationship between them. Furthermore, Bartlett's test of sphericity was significant, which is important for ensuring the elements are sufficiently correlated to carry out this type of analysis (López-Aguado \& GutiérrezProvecho, 2019).

Regarding the results of the EFA, Table 1 presents the values obtained with respect to the mean, asymmetry, and kurtosis by each of the elements of the scale.

Table 1. Mean, skewness, and kurtosis of the elements that make up the LPAPSM scale

\begin{tabular}{lccc}
\hline Item & Mean & Skewness & Kurtosis \\
\hline My daily use of SM has increased. & 4.20 & -1.404 & 1.251 \\
Watching a video of other people doing PA motivates me to train. & 3.43 & -0.422 & -0.623 \\
Sharing my achievements through SM motivates me to keep training. & 3.18 & -0.162 & -1.036 \\
SM can help make new sporting disciplines, training proposals, or exercises visible. & 4.39 & -1.349 & 2.131 \\
I have learned about new disciplines, training proposals, or exercises through SM. & 3.59 & -0.602 & -0.548 \\
SM facilitates the promotion of PA during lockdown. & 4.61 & -1.910 & 5.128 \\
SM is more important in promoting PA and sports during the lockdown than before. & 4.45 & -1.472 & 2.118 \\
$\begin{array}{l}\text { After confinement, I will continue to use SM to follow or participate in training } \\
\text { proposals. }\end{array}$ & 3.59 & -0.599 & -0.399 \\
\hline
\end{tabular}

The results of the EFA show that a factor is identified in which the eight items that make up the LPAPSM scale are grouped (see Table 2), with weights ranging from .41 to .66. The adjustment of the proposed model is adequate, since the RMSR value is below $.50($ RMSR $=.08)$ and the GFI value is above $.95(\mathrm{GFI}=.97)$. Finally, in terms of scale reliability analysis, Cronbach's alpha shows a value of .74, which is thus above the recommended value of .70 (Hair et al., 2006).

Table 2. Factorial structure of the LPAPSM scale

\begin{tabular}{lcc}
\hline Factor 1 LPAPSM & F1 & Com. \\
\hline My daily use of SM has increased. & .43 & .18 \\
Watching a video of other people doing PA motivates me to train. & .63 & .39 \\
Sharing my achievements through SM motivates me to keep training. & .43 & .18 \\
SM can help make new sporting disciplines, training proposals, or exercises visible. & .66 & .43 \\
I have learned about new disciplines, training proposals, or exercises through SM. & .62 & .39 \\
SM facilitates the promotion of PA during the lockdown. & .48 & .23 \\
SM is more important in promoting PA and sports during the lockdown than before. & .41 & .17 \\
After confinement, I will continue to use SM to follow or participate in training proposals. & .59 & .35 \\
\hline
\end{tabular}

Note: $\mathrm{Com}=$ communality; $\mathrm{RMSR}=.08 ; \mathrm{GFI}=.97$. 
Concerning the procedure for administering the questionnaire, the participants completed it online from April 6 to April 12, 2020. This time period was within the fourth week of the Spanish lockdown decreed by the Spanish Government on March 14, 2020, which entered into effect on the following day and limited citizen mobility to essential functions. Consequently, students did not return to the classroom and instead finished the academic year online. The statistical package SPSS 23.0 was used to analyze the data obtained as part of the quantitative approach through a descriptive analysis and inferential statistics testing (t-test).

\section{Results}

\section{Sociodemographics and SM usage patterns}

First, we wanted to understand the general habits of students' use of SM in their private lives. A total of $93.14 \%$ of the participants indicated that they used SM daily, with $66.86 \%$ spending less than two hours a day and $33.14 \%$ spending more than two hours a day. Students were also asked about their perceptions of whether their use of SM was excessive and what they thought of the population's daily use of SM. The majority of the students (98.29\%) thought they spent too many hours a day on SM. Furthermore, regarding their perceptions of the population's use of SM, $54.29 \%$ of them thought that people spend too many hours on SM, while $45.71 \%$ disagreed.

We also attempted to learn about the devices that students use to access SM and where they learned how to use SM (see Table 3). Almost all of the students reported accessing SM through their smartphones (98.29\%). Most indicated that they learned to use SM on their own (80\%), some learned to use SM through their friends (18.86\%), and a small percentage of students indicated that they learned to use SM at university (1.49\%).

Table 3. Devices used to access SM and how students learned to use SM

\begin{tabular}{lcccc}
\hline What is the device you use most to access SM? & Smartphone & Tablet & Laptop & Total \\
\hline Male & $131(97.76)$ & $1(.75)$ & $2(1.49)$ & $134(76.57)$ \\
Female & $41(100)$ & 0 & 0 & $41(23.43)$ \\
Total & $172(98.29)$ & $1(.57)$ & $2(1.14)$ & 175 \\
\hline How did you learn to use SM? & On my own & With friends & At university & Total \\
\hline Male & $108(80.60)$ & $24(17.91)$ & $2(1.49)$ & $134(76.57)$ \\
Female & $32(78.05)$ & $9(21.95)$ & 0 & $41(23.43)$ \\
Total & $140(80)$ & $33(18.86)$ & $2(1.14)$ & 175 \\
\hline
\end{tabular}

Note: percentage in parentheses.

The next aspect examined was the importance that students give to SM in their daily lives (see Table 4). In this case, the rating scale was from 1 to 10 , with 1 agreeing that SM is very unimportant and 10 considering it very important. In this area, males obtained higher scores than females, although after making a comparison of means employing a t-test for independent samples, such differences were not significant $(\mathrm{p}>.05)$.

Table 4. Comparison of means on the importance of SM in life

\begin{tabular}{lccc}
\hline & $\mathrm{n}$ & Mean & $\mathrm{SD}$ \\
\hline Male & $134(76.57)$ & 7.19 & 1.57 \\
Female & $41(23.43)$ & 6.95 & 1.50 \\
\hline
\end{tabular}

Note: percentage in parentheses; $\mathrm{SD}=$ standard deviation. tice PA was confirmed; gender was shown to be related to a greater use of SM for practicing PA, with women obtaining a higher percentage in proportion.

\section{COVID-19 lockdown SM usage patterns}

This research aimed to identify the SM habits of the participants during the lockdown, specifically in the area of viewing or practicing PA. First, practically all participants viewed PA proposals on SM (96.83\%) during the lockdown. Second, $67.16 \%$ of men and $85.37 \%$ of women used SM to practice PA (see Table 5). Finally, we employed statistical analysis to determine whether visualization habits changed according to gender. The results of this study indicate that gender did not have a significant relationship with visualizing PA proposals on SM $(p>.05)$. Gender was not related to visualizing PA proposals on SM. However, the relationship between gender and using SM to prac-

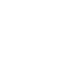


Table 5. Viewing PA on SM and using SM for PA

\begin{tabular}{lcccc}
\hline Have visualized PA on SM & Yes & No & Total & P \\
\hline Male & $51(98.08)$ & $1(1.92)$ & $52(82.54)$ & \\
Female & $10(90.91)$ & $1(9.09)$ & $11(17.46)$ & \\
Total & $61(96.83)$ & $2(3.17)$ & 63 & \\
\hline Have used SM for PA & Yes & No & Total & \\
\hline Male & $90(67.16)$ & $44(32.84)$ & $134(76.57)$ & \\
Female & $35(85.37)$ & $6(14.63)$ & $41(23.43)$ & $*$ \\
Total & $125(71.43)$ & $50(28.57)$ & 175 & \\
\hline
\end{tabular}

Note: percentage in parentheses; ${ }^{*} \mathrm{p}>.05$.

Afterwards, the participants were asked whether they thought SM was helpful for the practice of PA for people outside of the field of sports science. The results indicate that $100 \%$ of both the men and women thought SM was helpful for the practice of PA by the rest of the population during the lockdown period.

In addition, the students were asked explicitly about which SM platform they used to view proposals for PA during the lockdown (see Table 6). The results indicate that the majority of the students used YouTube and Instagram to view PA proposals, both in the case of men (YouTube, 91.79\%; Instagram, 91.79\%) and women (YouTube, 87.80\%; Instagram, 95.12\%). The students were also asked about which SM platforms they used for PA by themselves. As can be seen in Table 7, the SM platform that stands out the most in this regard is again YouTube, as $52.24 \%$ of the men and $60.98 \%$ of the women declared that they used this platform to practice PA during the lockdown. As before, Instagram came in second place, with $34.33 \%$ of the men and $60.98 \%$ of the women reporting using this medium to practice PA, despite the fact that the percentages show a greater difference than what they previously showed, especially in the case of Instagram.

Table 6. SM platforms on which students saw PA proposals during the lockdown

\begin{tabular}{|c|c|c|c|c|c|c|c|c|c|c|c|c|c|c|c|c|}
\hline & \multicolumn{2}{|c|}{ Facebook } & \multicolumn{2}{|c|}{ YouTube } & \multicolumn{2}{|c|}{ Twitter } & \multicolumn{2}{|c|}{ LinkedIn } & \multicolumn{2}{|c|}{ Instagram } & \multicolumn{2}{|c|}{ Snapchat } & \multicolumn{2}{|c|}{ TikTok } & \multicolumn{2}{|c|}{ WhatsApp } \\
\hline & No & Yes & No & Yes & No & Yes & No & Yes & No & Yes & No & Yes & No & Yes & No & Yes \\
\hline Male (134) & $\begin{array}{c}85 \\
(63.43)\end{array}$ & $\begin{array}{c}49 \\
(36.57)\end{array}$ & $\begin{array}{c}11 \\
(8.21)\end{array}$ & $\begin{array}{c}123 \\
(91.79)\end{array}$ & $\begin{array}{c}91 \\
(67.91)\end{array}$ & $\begin{array}{c}43 \\
(32.09)\end{array}$ & $\begin{array}{c}63 \\
(47.01)\end{array}$ & $\begin{array}{c}71 \\
(52.99)\end{array}$ & $\begin{array}{c}11 \\
(8.21)\end{array}$ & $\begin{array}{c}123 \\
(91.79)\end{array}$ & $\begin{array}{c}134 \\
(100)\end{array}$ & 0 & $\begin{array}{c}88 \\
(65.67)\end{array}$ & $\begin{array}{c}46 \\
(34.33)\end{array}$ & $\begin{array}{c}70 \\
(52.24)\end{array}$ & $\begin{array}{c}64 \\
(47.76)\end{array}$ \\
\hline \multirow[t]{3}{*}{ Female (41) } & $\begin{array}{c}22 \\
(53.66)\end{array}$ & $\begin{array}{c}19 \\
(46.34)\end{array}$ & $\begin{array}{c}5 \\
(12.20)\end{array}$ & $\begin{array}{c}36 \\
(87.80)\end{array}$ & $\begin{array}{c}37 \\
(90.24)\end{array}$ & $\begin{array}{c}4 \\
(9.76)\end{array}$ & $\begin{array}{c}17 \\
(41.46)\end{array}$ & $\begin{array}{c}24 \\
(58.54)\end{array}$ & $\begin{array}{c}2 \\
(4.88)\end{array}$ & $\begin{array}{c}39 \\
(95.12)\end{array}$ & $\begin{array}{c}40 \\
(97.56)\end{array}$ & $\begin{array}{c}1 \\
(2.44)\end{array}$ & $\begin{array}{c}27 \\
(65.85)\end{array}$ & $\begin{array}{c}14 \\
(34.15)\end{array}$ & $\begin{array}{c}24 \\
(58.54)\end{array}$ & $\begin{array}{c}17 \\
(41.46)\end{array}$ \\
\hline & \multicolumn{2}{|c|}{ Pinterest } & \multicolumn{2}{|c|}{ Vimeo } & \multicolumn{2}{|c|}{ MySpace } & \multicolumn{2}{|c|}{ Tumblr } & \multicolumn{2}{|c|}{ Moodle } & \multicolumn{2}{|c|}{ Blogs } & \multicolumn{2}{|c|}{ Wikis } & \multicolumn{2}{|c|}{ None } \\
\hline & No & Yes & No & Yes & No & Yes & No & Yes & No & Yes & No & Yes & No & Yes & No & Yes \\
\hline Male (134) & $\begin{array}{c}132 \\
(98.51)\end{array}$ & $\begin{array}{c}2 \\
(1.49)\end{array}$ & $\begin{array}{c}132 \\
(98.51)\end{array}$ & $\begin{array}{c}2 \\
(1.49)\end{array}$ & $\begin{array}{c}134 \\
(100)\end{array}$ & 0 & $\begin{array}{c}134 \\
(100)\end{array}$ & 0 & $\begin{array}{c}131 \\
(97.76)\end{array}$ & $3(2.24)$ & $\begin{array}{c}123 \\
(91.79)\end{array}$ & $\begin{array}{c}11 \\
(8.21)\end{array}$ & $\begin{array}{c}133 \\
(99.25)\end{array}$ & $1(.75)$ & $\begin{array}{c}132 \\
(98.51)\end{array}$ & $2(1.49)$ \\
\hline Female (41) & $\begin{array}{c}40 \\
(97.56)\end{array}$ & $\begin{array}{c}1 \\
(2.44)\end{array}$ & $\begin{array}{c}41 \\
(100)\end{array}$ & 0 & $\begin{array}{c}41 \\
(100)\end{array}$ & 0 & $\begin{array}{c}41 \\
(100)\end{array}$ & 0 & $\begin{array}{c}40 \\
(97.56)\end{array}$ & $1(2.44)$ & $\begin{array}{c}38 \\
(92.68)\end{array}$ & $\begin{array}{c}3 \\
(7.32)\end{array}$ & $\begin{array}{c}41 \\
(100)\end{array}$ & 0 & $\begin{array}{c}41 \\
(100)\end{array}$ & 0 \\
\hline
\end{tabular}

Note: percentage in parentheses.

Finally, the students were asked about different aspects of the relationship between SM and the practice of PA during the COVID-19 lockdown to gain a better understanding of their perceptions of the use of SM for the visualization or promotion of PA. The results were measured on a scale of 1 to 5, where 1 indicated total disagreement with the statement and 5 indicated total agreement. The results (see Table 8) show that all of the values of both males and females were above the central value of the scale. In terms of mean ratings by gender, the best ratings for both men and women appear in the item related to the facilitating role of SM in promoting PA during the lockdown, with means of $4.57( \pm .68)$ and $4.51( \pm .51)$, respectively. Likewise, it can be observed that the worst evaluation also coincides in males and females: the statement about sharing achievements as motivation to continue training, with mean values of $3.19( \pm 1.32)$ and $3.15( \pm 1.32)$, respectively. Concerning the comparison between genders, a t-test showed no significant differences according to this gender variable $(\mathrm{p}>.05)$. 
Table 7. SM platforms students used to practice PA proposals during the lockdown

\begin{tabular}{|c|c|c|c|c|c|c|c|c|c|c|c|c|c|c|c|c|}
\hline & \multicolumn{2}{|c|}{ Facebook } & \multicolumn{2}{|c|}{ YouTube } & \multicolumn{2}{|c|}{ Twitter } & \multicolumn{2}{|c|}{ LinkedIn } & \multicolumn{2}{|c|}{ Instagram } & \multicolumn{2}{|c|}{ Snapchat } & \multicolumn{2}{|c|}{ TikTok } & \multicolumn{2}{|c|}{ WhatsApp } \\
\hline & No & Yes & No & Yes & No & Yes & No & Yes & No & Yes & No & Yes & No & Yes & No & Yes \\
\hline Male (134) & $\begin{array}{c}128 \\
(95.52)\end{array}$ & $\begin{array}{c}6 \\
(4.48)\end{array}$ & $\begin{array}{c}64 \\
(47.76)\end{array}$ & $\begin{array}{c}70 \\
(52.24)\end{array}$ & $\begin{array}{c}126 \\
(94.03)\end{array}$ & $\begin{array}{c}8 \\
(5.97)\end{array}$ & $\begin{array}{c}132 \\
(98.51)\end{array}$ & $2(1.49)$ & $\begin{array}{c}88 \\
(65.67)\end{array}$ & $\begin{array}{c}46 \\
(34.33)\end{array}$ & $\begin{array}{c}133 \\
(99.25)\end{array}$ & $\begin{array}{c}1 \\
(.75)\end{array}$ & $\begin{array}{c}132 \\
(98.51)\end{array}$ & $\begin{array}{c}2 \\
(1.49)\end{array}$ & $\begin{array}{c}115 \\
(85.82)\end{array}$ & $\begin{array}{c}19 \\
(14.18)\end{array}$ \\
\hline \multirow[t]{3}{*}{ Female (41) } & $\begin{array}{c}39 \\
(95.12)\end{array}$ & $\begin{array}{c}2 \\
(4.88)\end{array}$ & $\begin{array}{c}16 \\
(39.02)\end{array}$ & $\begin{array}{c}25 \\
(60.98)\end{array}$ & $\begin{array}{c}40 \\
(97.56)\end{array}$ & $\begin{array}{c}1 \\
(2.44)\end{array}$ & $\begin{array}{c}36 \\
(87.80)\end{array}$ & $\begin{array}{c}5 \\
(12.20)\end{array}$ & $\begin{array}{c}16 \\
(39.02)\end{array}$ & $\begin{array}{c}25 \\
(60.98)\end{array}$ & $\begin{array}{c}41 \\
(100)\end{array}$ & 0 & $\begin{array}{c}38 \\
(92.68)\end{array}$ & $\begin{array}{c}3 \\
(7.32)\end{array}$ & $\begin{array}{c}37 \\
(90.24)\end{array}$ & $\begin{array}{c}4 \\
(9.76)\end{array}$ \\
\hline & \multicolumn{2}{|c|}{ Pinterest } & \multicolumn{2}{|c|}{ Vimeo } & \multicolumn{2}{|c|}{ MySpace } & \multicolumn{2}{|c|}{ Tumblr } & \multicolumn{2}{|c|}{ Moodle } & \multicolumn{2}{|c|}{ Blogs } & \multicolumn{2}{|c|}{ Wikis } & \multicolumn{2}{|c|}{ None } \\
\hline & No & Yes & No & Yes & No & Yes & No & Yes & No & Yes & No & Yes & No & Yes & No & Yes \\
\hline Male (134) & $\begin{array}{c}133 \\
(99.25)\end{array}$ & $\begin{array}{c}1 \\
(.75)\end{array}$ & $\begin{array}{c}134 \\
(100)\end{array}$ & 0 & $\begin{array}{c}133 \\
(99.25)\end{array}$ & $\begin{array}{c}1 \\
(.75)\end{array}$ & $\begin{array}{c}134 \\
(100)\end{array}$ & 0 & $\begin{array}{c}134 \\
(100)\end{array}$ & 0 & $\begin{array}{c}133 \\
(99.25)\end{array}$ & $\begin{array}{c}1 \\
(.75)\end{array}$ & $\begin{array}{c}134 \\
(100)\end{array}$ & 0 & $\begin{array}{c}96 \\
(71.64)\end{array}$ & $\begin{array}{c}38 \\
(28.36)\end{array}$ \\
\hline Female (41) & $\begin{array}{c}40 \\
(97.56)\end{array}$ & $\begin{array}{c}1 \\
(2.44)\end{array}$ & $\begin{array}{c}40 \\
(97.56)\end{array}$ & $\begin{array}{c}1 \\
(2.44)\end{array}$ & $\begin{array}{c}41 \\
(100)\end{array}$ & 0 & $\begin{array}{c}41 \\
(100)\end{array}$ & 0 & $\begin{array}{c}40 \\
(97.56)\end{array}$ & $\begin{array}{c}1 \\
(2.44)\end{array}$ & $\begin{array}{c}40 \\
(97.56)\end{array}$ & $\begin{array}{c}1 \\
(2.44)\end{array}$ & $\begin{array}{c}41 \\
(100)\end{array}$ & 0 & $\begin{array}{c}36 \\
(87.80)\end{array}$ & $\begin{array}{c}5 \\
(12.20)\end{array}$ \\
\hline
\end{tabular}

Note: percentage in parentheses.

Table 8. Perceptions regarding the relationship of SM use and PA during the lockdown

\begin{tabular}{lcccc}
\hline & & $\mathrm{n}$ & $\mathrm{Mean}$ & $\mathrm{SD}$ \\
\hline My daily use of SM has increased. & $\mathrm{M}$ & 134 & 4.18 & 1.06 \\
& $\mathrm{~F}$ & 41 & 4.27 & 1.18 \\
Watching videos of other people doing PA motivates me to train. & $\mathrm{M}$ & 134 & 3.40 & 1.17 \\
& $\mathrm{~F}$ & 41 & 3.51 & 1.25 \\
Sharing my achievements through SM motivates me to keep training. & $\mathrm{M}$ & 134 & 3.19 & 1.32 \\
& $\mathrm{~F}$ & 41 & 3.15 & 1.32 \\
SM can help make new sporting disciplines, training proposals, or exercises visible. & $\mathrm{M}$ & 134 & 4.35 & .77 \\
& $\mathrm{~F}$ & 41 & 4.54 & .75 \\
& $\mathrm{M}$ & 134 & 3.52 & 1.19 \\
I have learned about new disciplines, training proposals, or exercises through SM. & $\mathrm{F}$ & 41 & 3.83 & 1.26 \\
& $\mathrm{M}$ & 134 & 4.57 & .68 \\
SM facilitates the promotion of PA during the lockdown. & $\mathrm{F}$ & 41 & 4.71 & .51 \\
& $\mathrm{M}$ & 134 & 4.41 & .83 \\
SM is more important in promoting PA and sports during the lockdown than before. & $\mathrm{F}$ & 41 & 4.56 & .59 \\
& $\mathrm{M}$ & 134 & 3.51 & 1.19 \\
After the lockdown, I will continue to use SM to follow or participate in training & $\mathrm{F}$ & 41 & 3.88 & 1.08 \\
proposals.
\end{tabular}

Note: $\mathrm{M}=$ male; $\mathrm{F}=$ female; $\mathrm{n}=$ sample size $\mathrm{SD}=$ standard deviation.

\section{Discussion}

Concerning the general use of SM, it is clear that the majority of the students use SM daily, which coincides with what some studies have indicated regarding the important role that SM has in the day-to-day life of young people (Evans, 2014; Osgerby \& Rush, 2015; Zachos et al., 2018). Furthermore, it should be noted that almost all of the students $(98.29 \%)$ thought they used SM too much. This could suggest that SM use causes harm (e.g., sleep disturbances, low self-esteem, exposure to fake news, or other issues such as trolling or cyberbullying), as some 
studies have pointed out (e.g., Baccarella et al., 2018; Bailin et al., 2014). Given these risks, it would be appropriate for students at different educational stages to be trained in using these tools responsibly. The smartphone is the most widely used digital device for accessing SM, a tool that accompanies students practically all day long. Furthermore, smartphones were even more important during the lockdown when accessing content. As stated by Angosto et al. (2020), sports managers ought to consider use of these digital devices as an opportunity to expose customers and new audiences to their products.

Only $2 \%$ of students indicated that they learned to use SM at university, which is a remarkable result with important implications. Given the importance of SM in people's personal and professional lives (Zachos et al., 2018), it is striking that students indicated they did not learn to use SM at university. Considering that the students have grown up in a digital world (Adams et al., 2018) and that future professionals in the sports industry must possess digital skills (Manning et al., 2017), sports science curricula should be adapted to the current reality of society and the PA and sports sector. Indeed, if SM can help attract and inspire people to be more active and participate in sports, as Hayes (2020) points out, it is important to train students to use SM for this purpose. This is particularly important given that COVID-19 has further advanced the digitalization of the sports industry and social and mobility restrictions continue to occur in response to the continuation of the pandemic. These changes to curricula would probably facilitate students' future incorporation into the labor market and, according to Dinning (2017), the ultimate aim of universities is to develop employable graduates. In any case, this number (2\%) is in line with what has been reported by authors such as Manca and Ranieri (2016a, 2016b), who point out that due to cultural resistance, pedagogical aspects, or institutional constraints, academic institutions and faculty are still not very inclined to include SM in different educational practices. Therefore, we concur with several authors (e.g., Manca \& Ranieri, 2016a, 2016b; Manning et al., 2017) that it is necessary to provide support and training for educators to overcome these barriers. Concerning the habits of consuming SM to visualize or practice PA, most of the sample (96.83\%) visualized PA using these tools, and $71.43 \%$ engaged in PA during the lockdown. On the other hand, it is worth noting that significant gender differences have been found concerning engaging in PA at home using SM, with women doing so more than men. In this context, the results are not in line with the findings of studies measuring gender differences between men and women that have reported that men are more physically active than women regardless of age (Hands et al., 2016) or country (Bergier et al., 2016). This finding could encourage future studies to explore this issue in other populations to determine whether there are gender differences in the consumption of PA proposals on SM. The results of these studies could provide valuable information for sports managers and fitness trainers who offer these types of services.

YouTube is a SM platform for sharing videos, and Instagram began as a SM platform focused on the picture format but has evolved towards the video format thanks to its stories and recent Instagram Live function. These two platforms have emerged as the most popular for both viewing and practicing PA using SM at home. These results are logical since the video and live formats are the most suitable for viewing PA proposals on SM. It is also worth noting the emergence of LinkedIn, WhatsApp, and especially TikTok as SM platforms on which the students visualized PA proposals. These SM platforms represent opportunities for sports managers to reach more professional targets (LinkedIn), more confident familiar user targets such as family and friends (WhatsApp), or teenagers and youth (TikTok).

Finally, concerning the perceptions of sports science students about the use of SM to visualize or practice PA during the lockdown, it should be noted that all items exceed the central value of the measurement scale, showing the important value these tools have had for students to see others perform PA, gain motivation to do so themselves, learn new disciplines, or promote sports practice. This information reflects the versatility that SM can have in the sports industry and shows how these platforms can play an essential role in extreme situations such as a lockdown. Given the importance of being physically active during the lockdown period to avoid health problems (Constandt et al., 2020), and considering that the restrictions associated with the pandemic have adversely affected the sports industry (Ratten, 2020), relying on the use of SM to practice PA at home is likely a good option for the population. This is also notable considering the uncertainty about when, if ever, it will be possible to return to pre-COVID-19 normality in the sports industry and in spaces such as gyms and sports centers. Furthermore, lockdowns may occur in the future with additional COVID-19 waves. While increasing the vaccinated population and the extent of herd immunity may help prevent future lockdowns, the reality is that the emergence of new COVID-19 strains and variants may lead to selective confinement in specific regions around the world. In this study, the students expressed an intention to continue using SM to follow or participate in training proposals after the lockdown. Due to the circumstances described above, sports managers must continue to invest in and improve services offered through SM given the role these tools can play in the context of a pandemic. 


\section{Limitations and directions for future research}

While we believe this study is unique in its examination of the perceptions that undergraduate sports science students have about visualizing and practicing PA using SM during the COVID-19 lockdown, it is not without limitations. The study was carried out with a sample of PA and sports science students from a Spanish university. As in most of the studies in Spain based on this type of sample, there is a gender sample bias, with a considerably higher number of men than women (Garay et al., 2018). Therefore, from a gender perspective, caution should be advised when interpreting the results. In addition, due to the geographical location of the sample and the nature of the sample body, there may also be biases that reduce the generalizability of the results. Thus, it would be of great value to carry out similar studies among students from other countries or cultural backgrounds to determine whether differences exist. In addition, it would also be valuable to carry out specific studies with a sample that is not directly linked to the field of sport to identify other PA habits using SM in other populations. Furthermore, it could be valuable to test the psychometric properties of the LPAPSM scale with other samples, as well as its possible adaptation to other languages and similar situations in order to make cross-cultural comparisons.

In this study, participants were not asked about the specific use of sports apps (e.g., Freeletics, Jefit, SWEAT, Adidas Training, and Daily Yoga). These apps facilitate training at home or in other environments. Since these apps incorporate several social features such as a system of exchanging users' comments and photos, fitness challenges, and other competitive elements among users, they can be considered a specific new type of SM that could be labelled as sports apps or fitness apps. This type of SM is of great interest to the sports industry, and its user base is increasing. The use of sports apps in particular grew during the COVID-19 lockdown period. Therefore, future studies that investigate this type of SM, such as the one recently published by Angosto et al. (2020), are of great interest to both the industry and sports academies.

The effects of this situation on the big tech giants (e.g., Facebook, Google, and Amazon), which have made huge profits during the COVID-19 pandemic (Ovide, 2021; Yeo, 2021), also remain to be explored. The public health role of these corporations, which have reached collaboration agreements with public health authorities in the digital response to COVID-19 (Storeng \& de Bengy Puyvallée, 2021), needs to be investigated in future studies, especially in relation to the use of SM to promote and facilitate healthy PA.

Finally, although research linked to COVID-19 and sports has not been slow to arise through publications that explore the impact of the pandemic on sports, no studies have yet been published on the issue raised in this article. Considering this, and acknowledging the limitations outlined above, this study is a novelty in this field and provides results to be considered by sports managers and sports science faculties. Nevertheless, it needs to be complemented by further similar studies given the impact that COVID-19 is having on reshaping the entire sports industry.

\section{Conclusions and practical implications}

This study explored the perceptions of a group of undergraduate sports science students on visualizing and practicing PA using SM during the first COVID-19 lockdown period in Spain. This group will probably be the future managers or promoters of PA and the driving force behind both face-to-face and online sports products and services. Therefore, it is important for them to receive specific training in the university context so they may offer quality PA proposals on SM in the future. This issue is particularly pressing given how the process of digitalization has been accelerated by the pandemic and given that people are increasingly using SM in their daily personal and professional lives. However, the results of this study show that students do not feel they are given this training at university, which may form a knowledge gap that affects their professional future. Therefore, this study has implications at a pedagogical level, suggesting that professors, academic instructors, and trainers introduce SM in their classes to connect the reality and needs of the professional sports sector with the university sphere. In addition, universities should rethink their curricula by creating new formats that incorporate SM and by providing training support to faculty so that they can introduce SM in the classroom.

The results show how students of sports science used SM during the COVID-19 lockdown to visualize or practice PA. The results also show that students perceived these communication tools as channels through which to motivate themselves, promote PA, or learn about new training disciplines. YouTube and Instagram were the SM platforms chosen by sports science students for viewing or practicing PA. Beyond this SM platform, LinkedIn, WhatsApp, and TikTok are emerging as alternatives that can generate niche business opportunities for sports managers and fitness trainers. As for the gender variable, it has a significant influence in relation to the practice of PA using SM, with females being more likely to use SM for PA than men. This information has direct implications for 
professionals of the PA and sports industry (e.g., fitness center managers and personal trainers). Thus, it can be valuable for sports managers to adapt their proposals for PA on SM to target females or launch their proposals on the SM platforms that are most popular among the female population. Governments can use SM to carry out campaigns to promote healthy habits through the implementation of PA.

The results of this study also have broader implications for health. Confined populations naturally increase their sedentary habits. In this case, SM platforms have emerged as appropriate tools for promoting or facilitating PA that positively affects the health of the population. Governments can take advantage of SM to carry out PA promotion campaigns or develop specific health policies that reach out to citizens directly through SM.

Additionally, the study has implications for the specific field of study that has developed around the impact that COVID-19 has had on PA and the sports industry. In this sense, this study contributes to the existing literature through the creation and psychometric analysis of the properties of the LPAPSM scale, which can be used during possible future lockdowns that may unfortunately occur due to the expansion of the COVID-19 pandemic.

All in all, this study shows how SM has provided new channels for the sports industry to reach customers or generate new customers during the COVID-19 lockdown period. With the uncertainty of the pandemic's progression and potential for future lockdowns, sports managers must continue to explore the possibilities offered by SM. In short, SM offers an opportunity for sports managers to transform the negative situation caused by COVID-19 into something positive for the sports industry by providing new ways to bring sports products to the population.

\section{Ethics approval and informed consent}

The study was conducted according to the guidelines of the Declaration of Helsinki (World Medical Association, 2013).

\section{Competing interests}

There are no conflicts of interest associated with this manuscript, financial or otherwise.

\section{Funding}

This study did not receive any forms of funding.

\section{Acknowledgments}

The first author of this work is grateful for the support of the predoctoral contract "FPU15/05670" granted by the Spanish Ministry of Science, Innovation, and Universities, and by the postdoctoral contract for scientific excellence in the development of the "Plan Propio de I+D+i", co-financed by the European Social Fund.

The authors would also like to thank the two reviewers for their contributions, which improved the first draft of the manuscript.

\section{References}

Abeza, G., O’Reilly, N., Séguin, B., \& Nzindukiyimana, O. (2015). Social media Scholarship in Sport Management Research: A Critical Review. Journal of Sport Management, 29(6), 601-618. https://doi.org/10.1123/JSM.2014-0296

Adams, B., Raes, A., Montrieux, H., \& Schellens, T. (2018). "Pedagogical tweeting" in higher education: Boon or bane? International Journal of Educational Technology in Higher Education, 15(1), 19. https://doi.org/10.1186/s41239-018 $-0102-5$

Angosto, S., García-Fernández, J., Valantine, I., \& Grimaldi-Puyana, M. (2020). The intention to use fitness and physical activity apps: a systematic review. Sustainability, 12(16), 6641. https://doi.org/10.3390/su12166641

Baccarella, C. V., Wagner, T. F., Kietzmann, J. H., \& McCarthy, I. P. (2018). Social media? It's serious! Understanding the dark side of social media. European Management Journal, 36(4), 431-438. https://doi.org/10.1016/j. emj.2018.07.002

Bailin, A., Milanaik, R., \& Adesman, A. (2014). Health implications of new age technologies for adolescents. Current Opinion in Pediatrics, 26(5), 605-619. https://doi: 10.1097/mop.0000000000000140

Barkley, J. E., Lepp, A., Santo, A., Glickman, E., \& Dowdell, B. (2020). The relationship between fitness app use and physical activity behavior is mediated by exercise identity. Computers in Human Behavior, 108, 106313. https://doi. org/10.1016/j.chb.2020.106313 
Bergier, J., Bergier, B., \& Tsos, A. (2016). Variations in physical activity of male and female students from different countries. Iranian Journal of Public Health, 45(5), 705-707.

Constandt, B., Thibaut, E., De Bosscher, V., Scheerder, J., Ricour, M., \& Willem, A. (2020). Exercising in times of lockdown: An analysis of the impact of COVID-19 on levels and patterns of exercise among adults in Belgium. International Journal of Environmental Research and Public Health, 17(11), 1-10. https://doi.org/10.3390/ijerph17114144

Coughlin, S. S., Caplan, L. S., \& Williams, V. (2019). Home-based physical activity interventions for breast cancer patients receiving primary therapy: A systematic review. Breast Cancer Research and Treatment, 178(3), 513-522. https://doi:10.1007/s10549-019-05424-4

Dinning, T. (2017). Preparing sports graduates for employment: Satisfying employers expectations. Higher Education, Skills and Work-Based Learning, 7(4), 354-368. https://doi.org/10.1108/HESWBL-02-2017-0017

Dwivedi, Y. K., Hughes, D. L., Coombs, C., Constantiou, I., Duan, Y., Edwards, J. S., Gupta, B., Lal, B., Misra, S., Prashant, P., Raman, R., Rana, N.P., Sharma, S.K., \& Upadhyay, N. (2020). Impact of COVID-19 pandemic on information management research and practice: Transforming education, work and life. International Journal of Information Management, 55, 102211. https://doi.org/10.1016/j.ijinfomgt.2020.102211

Elhai, J. D., Yang, H., McKay, D., \& Asmundson, G. J. (2020). COVID-19 anxiety symptoms associated with problematic smartphone use severity in Chinese adults. Journal of Affective Disorders, 274, 576-582. https://doi.org/10.1016/j. jad.2020.05.080

Evans, A. B., Blackwell, J., Dolan, P., Fahlén, J., Hoekman, R., Lenneis, V., McNarry, G., Smith, M., \& Wilcock, L. (2020). Sport in the face of the COVID-19 pandemic: Towards an agenda for research in the sociology of sport. European Journal for Sport and Society, 17(2), 85-95. https://doi.org/10.1080/16138171.2020.1765100

Evans, C. (2014). Twitter for teaching: can social media be used to enhance the process of learning? British Journal of Educational Technology, 45(5), 902-915. https://doi.org/10.1111/bjet.12099

Filo, K., Lock, D., \& Karg, A. (2015). Sport and social media research: A review. Sport Management Review, 18(2), 166181. https://doi.org/10.1016/j.smr.2014.11.001

Flynn, A., Allen, N. E., Dennis, S., Canning, C. G., \& Preston, E. (2019). Home-based prescribed exercise improves balance-related activities in people with Parkinson's disease and has benefits similar to centre-based exercise: A systematic review. Journal of Physiotherapy, 65(4), 189-199. https://doi.org/10.1016/j.jphys.2019.08.003

Gao, Z., \& Lee, J. E. (2019). Emerging technology in promoting physical activity and health: challenges and opportunities. Journal of Clinical Medicine, 8(11), 1830. https://doi.org/10.3390/jcm8111830

Garay, B., Elcoroaristizabal, E., Vizcarra, M. T., Prat, M., Serra, P., \& Soler, S. (2018). ¿Existe sesgo de género en los estudios de ciencias de la actividad física y el deporte? Retos, 34, 150-154. https://doi.org/10.47197/retos.v0i34.58846

Goethals, L., Barth, N., Guyot, J., Hupin, D., Celarier, T., \& Bongue, B. (2020). Impact of home quarantine on physical activity among older adults living at home during the COVID-19 pandemic: Qualitative interview study. Journal of Medical Internet Research, 3(1), e19007. https://doi:10.2196/19007

Hair, J. F., Black, W. C., Babin, B. J., Anderson, R. E., \& Tatham, R. (2006). Multivariate data analysis. Pearson University Press.

Hammami, A., Harrabi, B., Mohr, M., \& Krustrup, P. (2020). Physical activity and coronavirus disease 2019 (COVID19): specific recommendations for home-based physical training. Managing Sport and Leisure, 1-6. https://doi.org/1 $0.1080 / 23750472.2020 .1757494$

Hands, B., Parker, H., Larkin, D., Cantell, M., \& Rose, E. (2016). Male and female differences in health benefits derived from physical activity: implications for exercise prescription. Journal of Womens Health, Issues and Care, 5(4), 1000238. https://doi.org/10.4172/2325-9795.1000238

Hayes, M. (2020). Social media and inspiring physical activity during COVID-19 and beyond. Managing Sport and Leisure, 1-8. https://doi.org/10.1080/23750472.2020.1794939

Kaplan, A. M., \& Haenlein, M. (2010). Users of the world, unite! The challenges and opportunities of social media. Business Horizons, 53(1), 59-68. https://doi.org/10.1016/j.bushor.2009.09.003

Lloret-Segura, S., Ferreres-Traver, A., Hernández-Baeza, A., \& Tomás-Marco, I. (2014). Exploratory item factor analysis: a practical guide revised and updated. Anales de Psicología, 30(3), 1151-1169. https://doi.org/10.6018/ analesps.30.3.199361

López-Aguado, M., \& Gutiérrez-Provecho, L. (2019). Cómo realizar e interpretar un análisis factorial exploratorio utilizando SPSS. REIRE Revista d'Innovació i Recerca en Educació, 12(2), 1-14. https://doi.org/10.1344/ reire2019.12.227057

Manca, S., \& Ranieri, M. (2016a). Facebook and the others. Potentials and obstacles of Social Media for teaching in higher education. Computers \& Education, 95, 216-230. https://doi.org/10.1016/j.compedu.2016.01.012 
Manca, S., \& Ranieri, M. (2016b). "Yes for sharing, no for teaching!": Social media in academic practices. The Internet and Higher Education, 29, 63-74. https://doi.org/10.1016/j.iheduc.2015.12.004

Manning, R., Keiper, M., \& Jenny, S. (2017). Pedagogical innovations for the millennial sport management student: Socrative and Twitter. Sport Management Education Journal, 11(1), 45-54. https://doi.org/10.1123/smej.2016-0014

Mutz, M., Müller, J., \& Reimers, A. K. (2021). Use of digital media for home-based sports activities during the COVID19 pandemic: results from the German SPOVID survey. International Journal of Environmental Research and Public Health, 18(9), 4409. https://doi.org/10.3390/ijerph18094409

Nabity-Grover, T., Cheung, C. M. K., \& Thatcher, J. B. (2020). Inside out and outside in: How the COVID-19 pandemic affects self-disclosure on social media. International Journal of Information Management, 55, 102188. https://doi. org/10.1016/j.ijinfomgt.2020.102188

Nicola, M., Alsafi, Z., Sohrabi, C., Kerwan, A., Al-Jabir, A., Iosifidis, C., Agha, M., \& Agha, R. (2020). The socioeconomic implications of the coronavirus pandemic (COVID-19): A review. International Journal of Surgery, 78, 185-193. https://doi.org/10.1016/j.ijsu.2020.04.018

Osgerby, J., \& Rush, D. (2015). An exploratory case study examining undergraduate accounting students' perceptions of using Twitter as a learning support tool. The International Journal of Management Education, 13(3), 337-348. https:// doi.org/10.1016/j.ijme.2015.10.002

Ovide, S. (2021, July 1). How big tech won the pandemic. The New York Times. Retrieved 06.08.21. from: https://www. nytimes.com/2021/04/30/technology/big-tech-pandemic.html

Parnell, D., Widdop, P., Bond, A., \& Wilson, R. (2020). COVID-19, networks and sport. Managing Sport and Leisure, 1-7. https://doi.org/10.1080/23750472.2020.1750100

Pekmezi, D., Ainsworth, C., Joseph, R. P., Williams, V., Desmond, R., Meneses, K., Bess, M., \& Demark-Wahnefried, W. (2017). Pilot trial of a home-based physical activity program for African American women. Medicine and Science in Sports and Exercise, 49(12), 2528-2536. https://doi.org/10.1249/MSS.0000000000001370

Ratten, V. (2020). Coronavirus and international business: An entrepreneurial ecosystem perspective. Thunderbird International Business Review, 62(5), 629-634. https://doi.org/10.1002/tie.22161

Schnitzer, M., Schöttl, S. E., Kopp, M., \& Barth, M. (2020). COVID-19 stay-at-home order in Tyrol, Austria: Sports and exercise behaviour in change? Public Health, 185, 218-220. https://doi.org/10.1016/j.puhe.2020.06.042

Shariat, A., Cleland, J. A., \& Hakakzadeh, A. (2020). Home-based exercises during the COVID-19 quarantine situation for office workers: A commentary. Work, 66(2), 381-382. https://doi:10.3233/WOR-203190

Stanford, F. C., \& Salles, A. (2021). Physician athletes promoting physical fitness through social media during the COVID-19 pandemic. Health Promotion Practice, 22(3), 295-297. https://doi.org/10.1177/1524839920988261

Stanton, R., To, Q. G., Khalesi, S., Williams, S. L., Alley, S. J., Thwaite, T. L., Fenning, A. S., \& Vandelanotte, C. (2020). Depression, Anxiety and Stress during COVID-19: Associations with Changes in Physical Activity, Sleep, Tobacco and Alcohol Use in Australian Adults. International Journal of Environmental Research and Public Health, 17(11), 4065. https://doi.org/10.3390/ijerph17114065

Storeng, K. T., \& de Bengy Puyvallée, A. (2021). The smartphone pandemic: How big tech and public health authorities partner in the digital response to Covid-19. Global Public Health, 16(8-9), 1482-1498. https://doi.org/10.1080/1744 1692.2021.1882530

Su, Y., Baker, B. J., Doyle, J. P., \& Yan, M. (2020). Fan engagement in 15 seconds: Athletes' relationship marketing during a pandemic via TikTok. International Journal of Sport Communication, 13(3), 436-446. https://doi.org/10.1123/ ijsc.2020-0238

Tanaka, J.S., \& Huba, G.H. (1989). A general coefficient of determination for covariance structure models under arbitrary GLS estimation. British Journal of Mathematical and Statistical Psychology, 42(2), 233-239. https://doi.org/10.1111/ j.2044-8317.1989.tb00912.x

Timmerman, M.E., \& Lorenzo-Seva, U. (2011). Dimensionality assessment of ordered polytomous items with Parallel analysis. Psychological Methods, 16(2), 209-220. https://doi.org/10.1037/a0023353

Wackerhage, H., Everett, R., Krüger, K., Murgia, M., Simon, P., Gehlert, S., Neuberger, E., Baumert, P., \& Schönfelder, M. (2020). Sport, exercise and COVID-19, the disease caused by the SARS-CoV-2 coronavirus. Deutsche Zeitschrift Fur Sportmedizin, 71(5), E1-E11. https://doi:10.5960/dzsm.2020.441

We Are Social (2020). Digital around the world in April 2020. Retrieved 12.08.20. from: https://wearesocial.com/ blog/2020/04/digital-around-the-world-in-april-

World Health Organization. (2020a). Coronavirus Disease (COVID-19): Weekly Epidemiological Update (25 April 2021). Retrieved 29.04.21. from: https://www.who.int/publications/m/item/weekly-epidemiological-update-on-covid-19--27-april-2021 
World Health Organization (2020b). Mental health and psychosocial considerations during the COVID-19 outbreak. Retrieved 07.08.20. from: https://www.who.int/docs/default-source/coronaviruse/mental-health-considerations. pdf?sfvrsn=6d3578af_2

World Medical Association. (2013). World Medical Association Declaration of Helsinki: ethical principles for medical research involving human subjects. JAMA, 310(20), 2191-2194. https://doi:10.1001/jama.2013.281053

Yeo, T. J. (2020). Sport and exercise during and beyond the COVID-19 pandemic. European Journal of Preventive Cardiology, 27(12), 1239-1241. https://doi.org/10.1177/2047487320933260

Yeo, S. (2021). Tech companies and public health care in the ruins of COVID. International Journal of Communication, 15, 1617-1636.

Zachos, G., Paraskevopoulou-Kollia, E.-A., \& Anagnostopoulos, I. (2018). Social media use in higher education: a review. Education Sciences, 8(4), 194. https://doi.org/10.3390/educsci8040194

This is Open Access article distributed under the terms of CC-BY-NC-ND 4.0 International License. 